\title{
2 From the Chain of Being to the Ladder of Creation
}

We begin with the emergence of a vision of the history of life on earth which sees it as a preordained advance towards the goal represented by the human race. This chapter charts the emergence of this version of what became known as evolutionism and shows how it initially defended itself against the encroachment of evidence suggesting that the process has no built-in direction. Illustrating the popularity and flexibility of the linear model of development in the life sciences provides an example we can then use to throw light on how that model also operated across a range of disciplines emerging to study human history and prehistory. In some cases, there were direct interactions between the various strands in which the model was applied, while in others there seems to have been a more general conceptual pressure at work encouraging thinkers to interpret their fields in terms of a goal-directed process of development.

Decades before what we today call 'evolution' became acceptable, naturalists began to challenge the traditional story that the world was created only a few thousand years ago. By around 1800 it was accepted that the earth had actually been in existence for a vast period of time, prompting various attempts to explain the succession of living forms being revealed by the fossil record. Not all focused on the idea of progress, but the record itself indicated a succession in the appearance of the higher forms of life, and for many naturalists this seemed to be evidence for a progressive trend in creation. At first there appeared to be no human fossils, so it could be assumed that we had appeared at the very end of the process. The Christian view that the creation of humankind was the key point of God's decision to create the cosmos encouraged many commentators to see the history of life as a progression aimed at this goal.

A template for this teleological approach already existed in the scala naturae or great chain of being. As Arthur O. Lovejoy's classic history shows, this apparently simple but actually quite complex model of the world had its origin in various strands of ancient thought. By the eighteenth century it had become a commonplace, widely invoked by moralists, religious thinkers, literary figures and naturalists to impose order on the apparently bewildering 
complexity of nature. It was not simply a description of the relationships between natural forms: in its original conception there was also a spiritual hierarchy stretching up to God. Humans occupied, in Alexander Pope's famous words, the crucial 'middle state', the point where the material scale below intersected with the spiritual scale above.

Here we are concerned primarily with the lower section of the chain, the scale of natural forms stretching from the simplest minerals through plants and animals up to humanity. This drew both on our sense that humans are somehow more significant than any other species and also on the commonsense appreciation that some animals seem 'higher' or more developed than others, and animals as a whole more complex than plants. This rough sense of a hierarchy based largely on assumed levels of consciousness was codified by the chain concept into a clearly defined structure, a unilinear pattern of relationships based on structural resemblances. Some of these resemblances are very superficial by the standards of modern biology, where the science of form (morphology) focuses on internal structure rather than external appearances.

The scala naturae (literally the 'ladder of nature') had obvious potential to be exploited as the basis for a temporal progression in the course of the earth's history. A ladder is meant to be climbed, although the metaphor of a chain carries no such implication. In Lovejoy's terminology, the chain or ladder was 'temporalized' in the late eighteenth century to give the first theories seeking to explain the history of life as a progression towards the human form. As William Bynum later noted, however, Lovejoy's focus on ideas led him to miss one of the darker applications of the chain, its use to justify the claim that the human races should be ranked into a hierarchy with whites at the top. ${ }^{1}$

As originally conceived, though, the chain was a purely static hierarchy. Its regular structure was seen as evidence that the universe was designed by the Creator to a rational plan, a plan that also identified the crucial status of humankind. To modern eyes it seems ridiculous to imagine that anyone could have seriously believed that all the species could be shoehorned into a single continuous sequence of forms. We have to bear in mind, however, that the idea was conceived long before Europeans had begun to explore the world geographically, let alone the fossil evidence for past life. The situation would change as the true diversity of living forms became apparent, but in the meantime any practical disadvantages for naturalists seeking to classify species were outweighed by the chain's philosophical, religious and moral advantages as a world-view. The technical difficulties that arose as ever more species had to be crammed into the sequence will emerge in Chapter 7.

${ }^{1}$ Bynum, 'The Great Chain of Being after Forty Years'. On the human implications of the chain see Chapter 3 below. 
To the eighteenth-century naturalists who first temporalized the chain it offered a way of showing how the Creator might have arranged things so that His plan for the eventual appearance of humankind would unfold in an orderly fashion. This seemed plausible when the complexity of the geological record was only just being recognized, and their ideas bear only a superficial resemblance to later efforts to reconstruct the history of life on earth. Their thinking was also limited in another, less obvious way. Like the naturalists of a later generation, they sought to establish a link between the history of life and the process by which the individual organism is produced, but their ideas about what was called the process of 'generation' were essentially materialistic. Conservative thinkers saw the growth of the embryo as a mechanical expansion of a pre-existing miniature or 'germ' originally created by God. The sequence of germs might embody a divine plan, but there was no significance in the actual process of growth.

It was the new philosophy of life associated loosely with the Romantic movement of the early nineteenth century that introduced a more dynamic view of generation, seeing it as an active process by which the unformed material of the fertilized ovum gradually develops the more complex structures of the mature form. Here was a concept that could turn the linear hierarchy of the chain into a model for a progressive trend in earth history. The ascent of a single hierarchy towards a final goal which we see in the embryo could be seen as a parallel to the development of life on earth, introducing what became the concept of 'recapitulation'. Focusing on the human embryo allowed its development to be seen as a speeded-up image of the whole history of life up to its intended goal. This link appeared in some of the early efforts to understand the fossil record in terms of a sequence of divine creations, but then exerted an even greater influence on theories of evolution.

There were other reasons why the linear version of the hierarchy of organic forms proved so resilient. Michel Foucault suggests that the 'classical' way of looking at things dominant in the eighteenth century encouraged the creation of ordering systems and assumed that nature must conform to our representations of it. The scala naturae was an obvious candidate for such a system. ${ }^{2}$ This may be an expression of an even deeper mind-set. Naturalists with no religious axe to grind were nevertheless convinced that there must be a regular order or pattern underlying the diversity of living forms. This viewpoint emerges from a personality type that has underlying psychological foundations. Some people just cannot bear to live with the possibility that the world might be nothing more than the product of haphazard events. The opposite personality type is willing to live with a certain level of uncertainty and

\footnotetext{
2 Foucault, Les mots et les choses, trans. as The Order of Things.
} 
unpredictability. ${ }^{3}$ The patterns sought by those who crave order at any cost are not necessarily linear. But a linear pattern is the simplest and most obvious, and it became a favourite among evolutionists who saw the development of life as the unfolding of a divine plan.

\section{The Scale of Nature}

By the early eighteenth century the chain of being had become the conventional image used by religious and literary figures seeking to convince their readers that the diversity of nature was based on a rational plan established by the Creator. Lovejoy's survey quotes numerous examples, of which Alexander Pope's lines from his Essay on Man (published 1733-4) are the best-known.

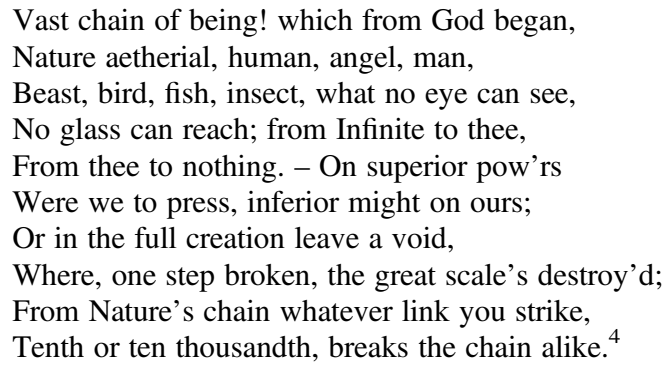

Pope's emphasis on the impossibility of any form being destroyed lest the chain be broken illustrates the viewpoint that made it so hard for naturalists to accept the possibility of extinction. Continuity must be complete to preserve the coherence of the whole. This leads in turn to what Lovejoy calls the principle of plentitude: if God is infinite then everything that could exist must actually exist or He would not have applied His powers to the full. By the same token there can be no distinct species: if we can imagine the intermediates between two known forms, then they must exist somewhere even if we have not found them yet. The implication is that the chain is really more like a continuous ribbon or rope.

Pope's identification of humanity's crucial position in the chain is equally well known. We are placed in the 'isthmus of a middle state' unable to decide whether we are human or beast, 'created half to rise and half to fall'. ${ }^{5}$ The implication that we are in a 'middle state' threatened the traditional belief that the spiritual part of our nature lifts us completely above the level of the 'beasts

${ }^{3}$ Bowler, 'Philosophy, Instinct, Intuition'.

${ }^{4}$ Pope, Essay on Man, epistle 1, lines 237-46, in The Works of Alexander Pope, vol. 7, p. 18.

5 Pope, Essay on Man, epistle 2, lines 1-10 and 15-18, in The Works of Alexander Pope, vol. 7, pp. 25-8. 
that perish'. Even before the chain was temporalized, religious thinkers and moralists had to confront the question of how this unique status could be maintained if there was complete continuity between the highest animals, usually presumed to be the apes, and ourselves.

To what extent was the chain accepted as a useful model of natural relationships by those who wanted to classify the increasing diversity of known living forms? It wasn't just the new species being discovered around the globe that made the chain seem increasingly like a procrustean bed into which a more complex world was being forced. Fossils too were becoming a problem and as Pope reminds us - the microscope was revealing a vast array of minute creatures at the bottom end of the scale.

In the Renaissance there had been little interest in constructing a coherent ordering of species, most observers being more interested in mere description. ${ }^{6}$ Many of the innovations in biological taxonomy from the late seventeenth century onwards either ignored the possibility of a linear arrangement or openly challenged it. Nevertheless the chain model did exert some influence, and the detailed survey by Henri Daudin is still worth reading as evidence of the ongoing conviction of some naturalists that they could recognize a linear pattern among the species they worked with. The botanist Anton Laurent de Jussieu took this approach seriously, as did Jean-Baptiste Lamarck - who figures prominently among those who sought to temporalize the chain. ${ }^{7}$

Other eighteenth-century naturalists have been associated with the chain by historians, but some caution is needed here. Concepts that originated as components of the chain model could take on a life of their own and could be used by those who had little interest in the possibility of a linear scale. This is most obvious with the principle of continuity, which inspired a wide range of naturalists to question the reality of species. Extracts from the comte de Buffon's classic Histoire naturelle, for instance, can be quoted to show that he sometimes argued for continuity. But this does not mean that he was interested in the idea of creating a linear scale. The same point can be made for Oliver Goldsmith's A History of Animated Nature of 1774, a successful popularization that drew much of its information from Buffon. Although hailed in one study for its use of the chain as an organizing principle, it actually described the animal kingdom in terms of multiple families more reminiscent of the branching tree of life. While always on the lookout for intermediates, Goldsmith was willing to admit that there were anomalies that did not fit into any of his families. ${ }^{8}$

\footnotetext{
6 See Ogilvie, The Science of Describing.

7 Daudin, Études d'histoire des sciences naturelles; on Jussieu and the chain see vol. 1, p. 207, and the introduction by Frans A. Stafleu to the reprint of Jussieu's Genera plantarum of 1789.

${ }^{8}$ For the original claim see Lynskey, 'Goldsmith and the Chain of Being'.
} 
Those who studied nature from a more philosophical perspective were more inclined to take the idea of a regular pattern such as the chain seriously. Of these the two best-remembered are Jean-Baptiste Robinet and Charles Bonnet. Both show how more conservative thinkers linked the idea of a rational plan of creation with a theory of reproduction that became popular immediately before the emergence of the modern view of embryological development. This was the theory of pre-existing germs, often called the preformation theory, according to which all living things originate from a miniature structure within the egg or sperm that already contains all the structures of the mature organism. The principle of emboitement or encapsulement held that all reproduction is based on the successive expansion of these miniatures, which had been originally created by God within the first members of each species, stored one within the other like a series of Russian dolls. ${ }^{9}$

This theory was introduced in the seventeenth century to reconcile the new mechanical philosophy inspired by developments in the physical sciences with the traditional belief that the universe was a stable divine creation. If - as Descartes and others claimed - the animal body was nothing more than a complex machine, it was hard to see how it could manufacture another equally complex structure in its own likeness. Even if this were possible, there could be no guarantee that successive generations would be exact enough copies to preserve the structure of the species and guarantee the stability of the organic world. For thinkers such as Robinet and Bonnet, the pre-existence of germs upheld their conviction that the Creator had provided the material universe with a mechanism capable of maintaining the order represented by the chain of being.

Lovejoy devotes fourteen pages to Robinet despite conceding that he tarnished his reputation by endorsing sailors' tall stories about the existence of mermen and mermaids. He certainly committed himself to the chain, devoting the seventh chapter of the first volume of his De la nature (1761-6) explicitly to the topic. But his later fascination with unlikely intermediates suggests that the principle of continuity was far more important to him. He rejected a suggestion made by P. L. M. de Maupertuis that there are now gaps in the sequence of creation opened up by catastrophic extinctions in the past. ${ }^{10}$

${ }^{9}$ On the theory of pre-existing germs see Pinto-Correia, The Ovary of Eve and Roger, Les sciences de la vie dans la pensée française du XVIIIe siècle (partial trans. as The Life Sciences in Eighteenth-Century French Thought); also Bowler, 'Preformation and Pre-existence in the Seventeenth Century'.

${ }^{10}$ Robinet, De la nature, vol. 4, pp. 7-9 on Leibnitz; vol. 1, pp. 20 and 64 on the fixity of species. The reference to Maupertuis's idea is in vol. 4, pp. 9-11; see the Essai de cosmologie in Maupertuis's Oeuvres (in the Lyons, 1766 ed.), vol. 1, pp. 72-3. See Murphy, 'JeanBaptiste Robinet'. 
As a consequence of his commitment to continuity Robinet found it impossible to admit the existence of discrete species: every point on the scale exists and is perpetuated by the mechanism of reproduction by pre-existing germs. In his first volume he argued that even minerals replenished themselves in this way, and in the fourth he suggested that all matter is, in fact, composed of germs with the potential to develop. At this point Robinet still saw the diversity of creation as a static system designed by God, with the linear pattern as only a limited guide to its structure. ${ }^{11}$

Charles Bonnet made his name with the discovery that aphids could reproduce by parthenogenesis, the process by which the females can produce offspring without the intervention of a male. Research with the microscope damaged his eyesight, and he spent the rest of his career reflecting on the relationships between God, nature and the human soul. He became the most eloquent proponent of the theory of pre-existing germs, assuming these were contained within the female ovum, so that in effect the whole human race had been enclosed within the ovaries of Eve. In the aphids the germs could evidently develop without the stimulus of the male semen. His Considérations sur les corps organizés of 1762 argued that the sequence of germs was originally formed by God within the first females of each species to ensure that the plan of creation would be preserved through succeeding generations. His system has been described by some historians as an effort to preserve the impression of absolute stability in the world. ${ }^{12}$ In fact, Bonnet conceded that the germ defined only the species to which the organism would belong, allowing limited variability because of environmental influences. Although generally supportive of the principle of continuity he accepted that there were distinct species in nature - although the gaps between then were very small. $^{13}$

Bonnet's Contemplation de la nature of 1764 develops his overall philosophy of nature. He reiterates his view that the germs guarantee that creation is a stable and coherent whole. ${ }^{14}$ In part 3 of the work, entitled 'Vue générale de la progression graduelle des êtres', he identifies the plan of creation with a linear chain of being. The sequence runs down the scale from humans through the various forms of vertebrates. Snakes lead to slugs and then to the rest of the

11 On continuity see Robinet, De la nature, vol. 4, p. 123; on mineral reproduction and all matter being germs see vol. 1, pp. 210-17, and vol. 4, p. 113 .

12 Whitman, 'Bonnet's Theory of Evolution' and 'The Palingenesia and the Germ Doctrine of Bonnet'; also Glass, 'Heredity and Variation in the Eighteenth-Century Concept of a Species'. For a more recent evaluation of Bonnet's philosophy see Anderson, Charles Bonnet and the Order of the Known.

13 Bonnet, Considérations sur les corps organizés, vol. 2, p. 314 (Oeuvres d'histoire naturelle et de philosophie, vol. 6, pp. 392-3) and on species ibid., vol. 1, p. 123 (Oeuvres, vol. 5, pp. 231-3).

14 Bonnet, Contemplation de la nature, vol. 1, pp. 154-64 (Oeuvres, vol. 7, p. 4). 


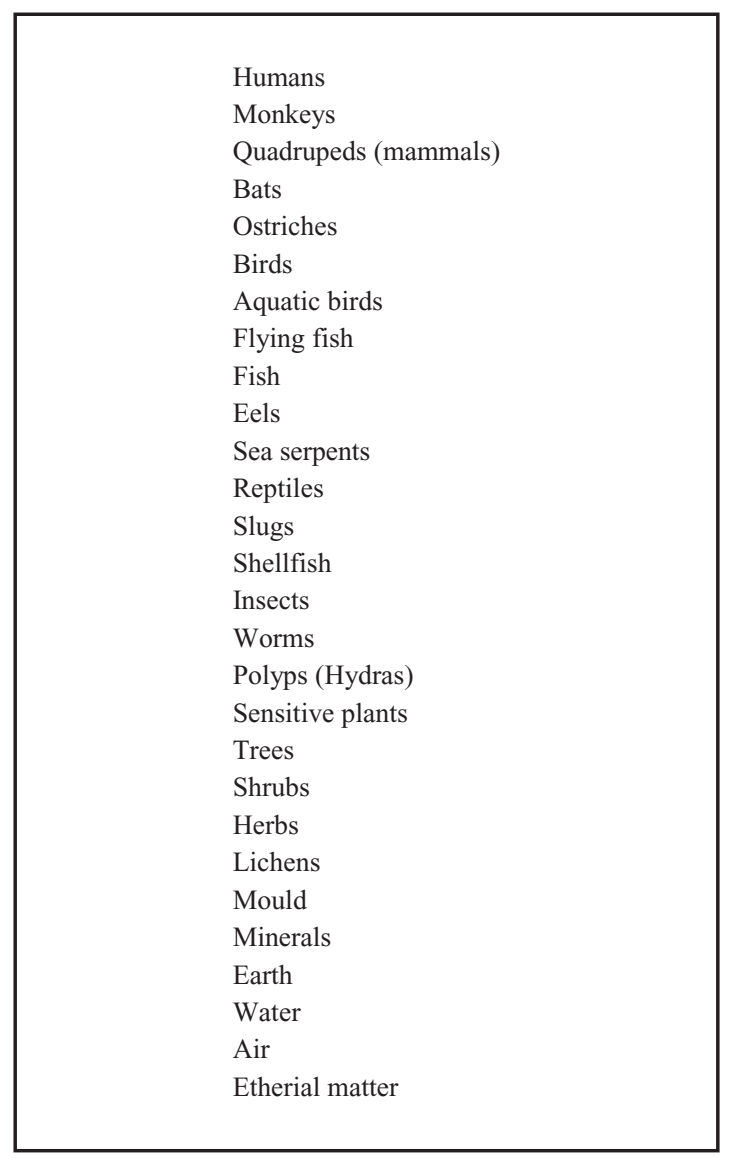

Figure 2.1 The chain of being according to Bonnet's Contemplation de la nature (1764). Bonnet does not provide such a representation himself; this is assembled according to the sequence described in his text.

invertebrates (the notion that any 'creepy-crawly' could have a structure as complex as a vertebrate was alien to the hierarchical vision of the time). Bonnet uses the polyp or freshwater hydra, whose regenerative powers had been discovered by Abraham Trembley, to bridge the gap between animals and plants and then creates a sequence down through the vegetable kingdom to moulds and minerals (see Figure 2.1).

Some of the intermediates used to preserve an impression of continuity seem incongruous today, although they would not have appeared ridiculous in an age that did not judge affinities on internal structure. Bonnet himself 
recognized that there were practical problems inherent in the effort to shoehorn nature into a unilinear sequence. He conceded that insects and shellfish were difficult to fit in, and seemed puzzled by the status of sea-lions and whales. ${ }^{15}$ Nevertheless his preference for a more or less linear hierarchy stretching down from humanity through the whole of the animal and vegetable kingdoms is apparent. If there were branches off the main stem, they were relatively insignificant.

The universe depicted in the Contemplation de la nature was essentially stable, but there was one suggestion of an in-built potential for future change. Bonnet had written extensively on the nature of the soul, dealing with what we call psychology today, and as a Christian he was convinced that every human soul would eventually be resurrected in a more perfect body. He suggested that there might be a second type of germ in addition to those encapsulated in women and intended for normal reproduction. Everyone, male and female, would contain a miniature destined to unfold into the better-endowed body to be enjoyed after resurrection; it would survive the death of the original body and lie dormant, waiting for the last trump. ${ }^{16}$

\section{The Chain Temporalized}

Robinet and Bonnet were cited by Lovejoy as examples of eighteenth-century thinkers who temporalized the chain of being. In their later works, both saw the possibility that the development of the germs could be programmed (to use a modern term) to unfold in a sequence that produced successively higher beings in the course of the earth's history. These ideas do not correspond to theories of transmutation or evolution as we understand it today because they do not involve the appearance of genuine novelties. Absolute stability is preserved in the sense that all the germs were still thought to have been created by God at the beginning of the universe. What unfolds is what was predestined to unfold.

Nevertheless, their ideas do recognize that the earth's populations have changed their appearance in the course of geological time. By the 1760s naturalists studying the earth's crust had demonstrated that the planet must be very old and had gone through major transformations in the course of its history. Robinet and Bonnet both appreciated the need to take this evidence into account. To this extent their ideas serve as a link between the original,

15 Contemplation de la nature, vol. 1, p. 59 on insects and shellfish (Oeuvres, vol. 7, pp. 133-4). On the chain see Anderson, Charles Bonnet and the Order of the Known, chap. 2, esp. pp. 39-40.

16 This is in part 4, chap. 13; see Contemplation de la nature, vol. 1, pp. 85-90 (Oeuvres, vol. 7, pp. 207-12). 
static conception of the chain and the theories of evolution proposed by J. B. Lamarck and others that would influence nineteenth-century evolutionism.

Robinet's later views are somewhat incoherent since they involve both speculations about progress and the idea of an organic 'prototype', a basic design from which many different forms can be developed. The latter emerged in a separate work and seems more like an anticipation of the branching model of evolution. ${ }^{17}$ The temporalization of the chain occurs in the fourth volume of De la nature, where he imagines that the germs of successively higher forms might unfold into real organisms in sequence over the course of ages. He hints that the first examples of a particular type of organism can unfold only in the body of the form immediately below on the scale. From this initial insight he later develops a vision of the natural world ascending a preordained hierarchy of organization towards the human form.

As for the order of the developments, I am sure that nature has always proceeded from the least composite to the more composite. The most complex organization that we know, and that which produces the most phenomena, is that of man. There would thus have been times when no human germ had developed. But how many millions of years or centuries were necessary to bring the human seed to maturity? How many manifestations to bring it forth? We are no longer in a position to say. There are no intervals, small or large, between the successive and neighbouring development. Nature passes from one to the other without discontinuity. ${ }^{18}$

If this brief passage is taken at face value it implies a progressive increase in the level of organization over geological time. The sequence of development would be predetermined by the germs, but the result would be a gradual ascent towards the human form.

Bonnet's temporalization of the chain drew on the suggestion he had already made that there might be another type of germ destined to provide the soul with a more perfect body at the resurrection. In his Palingénésie philosophique of 1769 he expands this process to cover the whole of creation. The first step in the argument was to extend resurrection to the whole of nature. At the same time as humans are resurrected in a higher form, so all the creatures lower in the scale will move a corresponding step upwards in the scale.

The same progression that we discover today between the different orders of organized beings will be observed, no doubt, in the future state of our globe; but it will follow other proportions determined by the degree of perfectibility of each species. Man, now transported to a new abode more suited to the eminence of his faculties, will leave to the ape and the elephant the first place which he occupied among the animals of our planet.

17 See Lovejoy, The Great Chain of Being, pp. 277-81, and Roger, Les sciences de la vie, pp. $650-1$.

18 Robinet, De la nature, vol. 4, p. 6 and quotation from p. 128 (my translation). 
In this universal restitution of the animals, there will thus be found a Newton or a Leibniz among the apes, a Perrault of a Vauban among the beavers. ${ }^{19}$

The same mechanism is then extended back in time to create a vision of the history of life as an ongoing sequence of resurrections, allowing all to ascend the scale of perfection.

Bonnet accepted that the earth had experienced a series of great catastrophes in the course of time, of which the Mosaic flood was but the last. He assumed that all life would be wiped out in each upheaval, but when the violence had died down, all souls would be resurrected in new bodies supplied by their germs. His chapter on the topic is devoted mostly to arguing that in each epoch the bodily forms would be pre-adapted to the new conditions, the Creator having anticipated what was needed. ${ }^{20}$ He gives only a hint that as conditions improved, so the level of organization would increase. The clearest indication that the steps would always be progressive is articulated later when the idea is extended to the whole universe: 'If His plan required that the sentient beings inhabiting a certain planet should pass successively through various subordinate degrees of perfection, He has pre-established from the beginning the means destined to increase the form of their perfection and has given them the whole extension that their nature can bear. ${ }^{21}$

Modern commentators have tended to assume that the main message of the Palingénésie focused on the historical progression of life. Stephen Gould presents it as an anticipation of the belief that the evolutionary progress of life is recapitulated in the development of the modern embryo (while conceding that for Bonnet himself there was no such development because the embryo simply expanded from a pre-existing miniature). ${ }^{22}$ The historians who insist that there is no anticipation of modern evolutionism here are correct in the sense that resurrection after death is not evolution, and the process is nothing more than the unpacking of potentials created by God. Yet the very fact that Bonnet was concerned to show that life had to be adapted to conditions that changed over geological time suggests that we should not dismiss his influence. He was widely read at the time, and was perceived as contributing to the expanding vision of earth history. If his contemporaries focused on the element of progress in his writing, his contribution to the process of temporalization cannot be ignored.

19 Bonnet, La palingénésie philosophique, part 3, vol. 1, p. 203 (Oeuvres, vol. 15, p. 219; my translation). On these developments see the studies cited in the previous section and my 'Bonnet and Buffon'.

${ }^{20}$ La palingénésie philosophique, part 1, chap. 6, vol. 1, pp. 236-62 (Oeuvres, vol. 15, pp. 254-84).

21 La palingénésie philosophique, part 14, vol. 2, p. 74 (Oeuvres, vol. 16, p. 74; my translation).

22 Gould, Ontogeny and Phylogeny, pp. 17-28. 


\section{Evolution in an Age of Revolution}

Bonnet's world-view was swept aside when Europe was traumatized by the French Revolution and the convulsions of the Napoleonic era. There was an increasing willingness to accept that nature was a dynamic rather than a static system, and the element of progress hinted at in the temporalized versions of the chain of being began to seem more prescient. The transformist theories proposed by Erasmus Darwin and Jean-Baptiste Lamarck are typical of this movement. Both were convinced that living structures can be modified over many generations to produce new forms of life, and both believed that in the long run the new forms achieved higher levels of organization. Both were also willing to accept that natural forces could produce at least primitive living structures from inorganic matter: the process known as spontaneous generation. The theory of pre-existing germs was swept aside, allowing the development of the individual organism to be seen as a genuinely creative process. What we now call evolution - transformism in the terminology of the time - depended on the gradual modification of the process of individual development over many generations.

All this seems a prelude to the more organic, developmental world-view of the early nineteenth-century Romantics and transcendentalists. Indeed Charles Gillispie's account of Lamarck's transformism identifies him with the Romantic movement. ${ }^{23}$ Few historians now accept this interpretation, seeing Lamarck instead as a thinker who expanded the mechanical philosophy of the Enlightenment by accepting that natural forces can play an active, creative role. This is not quite the same as the Romantic image of a dynamic, selforganizing nature, but it allowed the emergence of similar views on progressive development through time. The same approach underpinned the views of Erasmus Darwin, but his vision of progress was less structured than Lamarck's and was thus closer to the modern vision of branching development proposed by his grandson Charles.

Lamarck is remembered as one of the first evolutionists, although few realize just how different his transformism was from the modern Darwinian theory. He is identified with a hypothetical mechanism of adaptive evolution that is seen as the most obvious alternative to natural selection, superficially plausible although later challenged by modern genetics. This is the inheritance of acquired characteristics, often called 'Lamarckism', according to which purposeful modifications developed by the organism in the course of its life can be transmitted to its offspring and hence accumulate over the generations to modify the species. If this alternative were Lamarck's primary contribution,

23 Gillispie, 'Lamarck and Darwin in the History of Science'. 
then he could be included among those who promoted the open-ended, unstructured view of the evolutionary process. A diagram included in his main evolutionary text, the Philosophie zoologique of 1809 , is often seem as an early example of the branching-tree model of the development of life on earth. Yet most modern studies now present Lamarck in a very different light. He did see adaptation to the environment as an important transformative agent, but this was supplementary to a more fundamental force that drove living things steadily to mount a scale of organization that was, in principle, linear. The necessity of adapting to an ever-changing environment merely distorted the regularity of the fundamental hierarchy of organization.

Lamarck's theoretical views extended far beyond the transformism he proposed in the later part of his career and were highly controversial. But he was a working naturalist who made improvements of permanent value in the field of biological classification (taxonomy). Originally a botanist, he published a major survey of the French flora. In 1794 he was appointed a professor at the new Muséum d'Histoire Naturelle established by the revolutionary government and was assigned to the study of invertebrate animals. $\mathrm{He}$ improved invertebrate taxonomy in ways that are still considered fundamental today. One modern account of Lamarck's work (by Richard Burkhardt, Jr) is entitled The Spirit of System, indicating the importance of the drive to organize in his vision of nature. His Hydrogéologie contained an early account of earth history committed to the vision of vast changes over immeasurable periods of time. Here was a framework within which he could, in the middle part of his career, convert his originally static view of the plant and animal kingdoms into a developmental or evolutionary theory. This was expounded in his Philosophie zoologique of 1809 and in the introduction to his Histoire naturelle des animaux sans vertèbres of 1815-22.

Chapter 5 of part 1 of the Philosophie zoologique is devoted to the classification of animals and proclaims Lamarck's endorsement of a basically linear hierarchy of organization. The book's preliminary discourse contains a reference to Bonnet, suggesting that the latter had been unable to confirm the reality of the chain owing to the limited state on knowledge at the time. ${ }^{24}$ Lamarck did not accept the chain in its original form, because he saw the hierarchies of the plant and animal kingdoms as entirely separate, not one above the other. But within each kingdom there was a scale of organization, produced gradually

24 Lamarck, Zoological Philosophy, p. 12; in the edition cited the famous 'branching-tree' diagram is on p. 179. On the influence of the chain of being on Lamarck's thinking see the second volume of Daudin's Études d'histoire des sciences naturelles, esp. part 2, pp. 110-25, and Schiller, 'L'échelle des êtres et la série chez Lamarck'. More generally see Burkhardt, The Spirit of System; also Hodge, 'Lamarck's Science of Living Bodies'; Corsi, The Age of Lamarck; Jordanova, Lamarck; and Laurent, ed., Jean-Baptiste Lamarck. 
over time, and visible in the major groups if not in the individual genera and species where adaptation had produced additional modifications.

I shall show that nature, by giving existence in the course of long periods of time to all the animals and plants, has really formed a true scale in each of these kingdoms as regards the increasing complexity of organization; but that the gradations in this scale, which we are bound to recognize when we deal with objects according to their natural affinities, are only perceptible in the main groups of the general series, and not in the species or even in the genera. This fact arises from the extreme diversity of conditions in which the various races of animals and plants exist; for these conditions have no relation to the increasing complexity of organization ... ; but they produce anomalies or deviations in the eternal shape and characters which could not have been brought about solely by the growing complexity of organization. ${ }^{25}$

Lamarck thus recognized the diversification produce by adaptation, but saw it as distorting a linear scale of organization. His 'branching-tree' diagram was not meant as an evolutionary phylogeny; it is a representation of the divergences produced in the chain of being by external factors.

Lamarck did not see the array of living species as the end-points of a branching tree, because he did not think that all forms today share a common ancestry. This is apparent from the fact that he thought that the spontaneous generation of the simplest forms of life has gone on throughout the earth's history and is still at work today. He thought there was an active principle in nature which he identified with current electricity. This was then a newly discovered force, widely seen as an active principle and taken by many as something essential to life (Mary Shelley invokes it to explain how Frankenstein vivifies his artificial creation). Lamarck imagined it being able to work on gelatinous matter to produce very simple life forms. Electricity is also the force that operates the nervous system and hence controls the body, and he proposed that its constant activity tends to increase the level of the body's complexity. In the course of generations, the creatures thus steadily mount the scale of organization.

Lamarck's vision was one of parallel developments up a scale with some limited divergence. As soon as one line of advance sets off up the scale, another is founded by a further act of spontaneous generation, and so on throughout geological time. The oldest lines of development have risen furthest to give the highest animals of today. Middle-ranking creatures originated from lines founded later in the earth's history, while the lowest modern organisms have only recently been generated. Continuity is maintained by the constant activity of spontaneous generation (Lamarck did not accept the reality of species, nor the possibility of extinction). Evolution is an escalator on

25 Zoological Philosophy, p. 58. 
which forms rise in parallel, one behind the other, up the same scale of organization. There is some divergence caused by environmental factors, but nothing corresponding to the splitting of a lineage into two or more branches that occurs throughout the Darwinian tree of life. The lines that diverge have always been separate since their first, independent origins.

Lamarck accepted that, as the currently highest form, the human race had evolved from the oldest line of development, speculating that an ape-like creature had eventually developed an upright posture. ${ }^{26} \mathrm{He}$ cited the chimpanzee as an illustration of the ancestral form, but this was not to indicate that we had evolved from the modern apes, because they would belong to a separate line advancing behind us up the scale. Note the similarity to Bonnet's vision of the higher animals taking our place as we move one step further up at the resurrection. Lamarck would no doubt accept that the precise form of the human species was not predetermined, since some adaptive features were involved, but his system implied that something very like us, with the same advanced mental faculties, was an inevitable product of nature's activity.

Lamarck was also keen to stress that the progressive development of life was relevant to our understanding of human nature. Much of the Philosphie zoologique was devoted to his views on the physiology of the nervous system and their implications for mental activity. He insists that since our mental and moral faculties have a material basis, it is the zoologist who can throw most light on them. ${ }^{27}$ The human mind is an extension of the mental faculties developed through time in the animal kingdom, and an understanding of its origins will throw light on its functions and hence on the fields we now call psychology and sociology. Lamarck's views on these topics were in line with the group known as the idéologues, led by the abbé Condillac and P. G. J. Cabanis. They in turn were linked to Condorcet, a major contributor to the emerging idea of social progress. Lamarck certainly thought that a better understanding of our psychological nature should help us interact socially in a more effective fashion, but he does not seem to have shared Condorcet's optimism, perhaps because his own ideas were dismissed by Napoleon and the leader of French zoology, Georges Cuvier. The Philosophie zoologique ends with a complaint about the power of conservatives to block the emergence of innovative ideas. ${ }^{28}$

Cuvier rejected any notion of a linear arrangement, as did the more radical naturalists of the post-revolutionary era. The new approaches increasingly

26 Ibid., pp. 171-2; see Bowler, Theories of Human Evolution, pp. 61-2.

27 Zoological Philosophy, p. 287; part 2 of the book is on physiology, including Lamarck's views on spontaneous generation (chap. 6); part 3 is on the nervous system and psychology.

28 Ibid., pp. 404-5; Jordanova, Lamarck, chap. 9, gives a succinct account of his views on the latter topic. 
presented development as a divergent rather than a linear process. Yet there were still some naturalists who continued to look for a linear scale hidden within the complexity of living forms. Historians have uncovered a substantial body of French naturalists opposed to Cuvier and have noted their influence across the Channel in Britain. At least some of these opponents took up parts of Lamarck's thinking, including his hope of constructing a linear hierarchy of organization. Prominent among them was Henri de Blainville, who both championed the serial arrangement and used it constructively: he was the first to see the monotremes and marsupials as the most primitive mammals. Edinburgh anatomists including Robert Jameson and Robert Knox used the linear model, and Everard Home interpreted the duck-billed platypus as an intermediate in the chain. ${ }^{29}$

The absolutely linear chain of being was gone, but its influence lingered in these efforts to see a hierarchy linking the most basic categories of the animal kingdom. This was not necessarily evolutionism - de Blainville rejected Lamarck's transmutationism - but the fascination with the idea of a main line of progress in the history of life lingered on and would continue to influence evolutionary theories into the late nineteenth century.

\section{The Law of Parallelism}

In the early decades of the nineteenth century the repercussions of the age of revolution were expressed in the sciences as much as in wider cultural values. This was the age of Romanticism and the rise of idealist philosophies, but also a time in which radical materialism challenged the old social order. In the life sciences there were revolutionary developments in comparative anatomy and embryology, while studies of the fossil record provided the first hard evidence of a sequence of development in the history of life on earth. Nature itself was now seen as a creative system, a world-view in which the idea of progress could flourish. Bonnet's germ theory in which the embryo simply unfolded from a pre-existing miniature was replaced by an embryology which took epigenesis - the purposeful development of new structures - for granted. ${ }^{30}$

The chain of being too seemed under threat from the new 'biology' (a term now introduced to denote the systematic study of life). Comparative anatomists such as Cuvier focused on the internal structure of organisms, undermin-

${ }^{29}$ See Appel, 'Henri de Blainville and the Animal Series' and Jenkins, 'The Platypus in Edinburgh'. More generally see Corsi, The Age of Lamarck, esp. chap. 7.

30 On these developments see Appel, The Cuvier-Geoffroy Debate; Lenoir, The Strategy of Life; Nyhart, Biology Takes Form; and on the British radicals Desmond, The Politics of Evolution. 
ing the credibility of the superficial resemblances used to create an illusion of continuity in the chain. He divided the animal kingdom into four basic types and declared that they could not be ranked into a series leading up to the human form. The linear model survived, however, in a modified form among those embryologists who thought they could see a parallel between the sequence of development in the embryo of the highest form in any group and the linear hierarchy of classes they recognized within the group. In the vertebrates this sequence ran from the fish through the reptiles up to the mammals and the human form.

At the same time, studies of the earth's crust created the outlines of our modern view of the planet's history, confirming its vast antiquity and the immense changes it has undergone. Palaeontologists also began to reveal the history of life as recorded in the fossil record. By the 1840s the basic steps in the advance of animal life had been identified, and they corresponded to the same linear sequence seen in embryological development. The apparent parallel encouraged an assumption that there was a link between how the embryo develops towards maturity and how the animal kingdom has advanced towards its highest manifestation in the human form. To conservative thinkers within the Romantic movement the development of life was an expression of the creative activity of the deity or some equivalently purposeful force.

The possibility of retaining a linear framework within the variety of natural forms arose because everyone admitted that some organisms are more advanced than others in the sense that they are further removed from the most basic form of their type. As Karl Ernst von Baer insisted, a human embryo never looks like a mature fish, but fish and human embryos resemble each other up to a certain point in the process of development. In order to mature the fish embryo adds on fewer extra structures that the human does not have, which is why it was possible for some embryologists to think in terms of the human embryo passing through a fish-like stage at an early point in its development. From this assumption arises what was known as the 'law of parallelism', according to which phases in the development of the human embryo correspond to the hierarchy of classes in the vertebrate type. The human embryo is (in a generalized sense) first a fish, then a reptile and finally a mammal. When this is coupled with the revelation that this was the sequence in which the classes appear in the fossil record we get the 'recapitulation theory', in which the development of the human embryo recapitulates the progressive development of life on earth. ${ }^{31}$

The law of parallelism allowed the basis for a linear hierarchy of organization to be preserved even within a system that accepted the branching nature of

31 Gould's Ontogeny and Phylogeny provides a detailed history of the theory. 
development. All species represent the end-points of a diverging tree of relationships, but because we define one species (our own) as the highest, the line leading towards it becomes the main line of development, the trunk of the tree. All other lines are side-branches leading away from that main line. They no longer participate in the progressive trend and are by definition of lesser importance. Key elements of the chain of being are preserved: its linearity and its end-point in the human form.

The law could, in fact, be applied to any other branch in the tree of relationships, and much work in taxonomy was done on this basis. The Edinburgh anatomist Robert Edmond Grant - a political radical who interacted with Charles Darwin during the latter's student days - applied it in his work with the sponges. This involves the creation of multiple linear series. But as Grant would have been aware from his interest in Lamarck's evolutionism, most attention focused on the hierarchy of the vertebrate classes and humankind's position at the head of that series. Lorenz Oken and his fellow enthusiasts for the idealist view of the world known as Naturphilosophie began to argue that the development of the human embryo corresponds to the series to be seen in the animal kingdom as a whole. ${ }^{32}$ Naturalists knew there were branches in the tree of life, but most were dead-ends: only the main trunk led upwards to the goal represented by the human form.

J. W. von Goethe was the most influential source of what Robert Richards calls the 'Romantic conception of life', but his morphological and evolutionary theories placed most stress on the diversity of the developments that emerged from the archetypical form. It was Oken"s Naturphilosophie that served as the foundation for the law of parallelism. Goethe and Oken fell out over priority in their anatomical discoveries, and at the same time Oken adopted a more mystical style of exposition often based on cryptic declarations intended to startle those of a more mundane disposition. In his Elements of Physiophilosophy he stated that: 'The animal kingdom is only a dismemberment of the highest animal, i.e. Man.' He insisted on the law of parallelism in its most brutal form: 'Animals are only the persistent foetal stages or conditions of man.' The implication seems to be that the human embryo passes through stages that represent the mature forms of the various grades of the lower animals. Oken also declared that despite the diversity of animal forms and organs 'Each animal ranks therefore above the other; two of them never stand upon an equal plane or level.' This implies that the scale of nature is unilinear; otherwise one could imagine two branches independently reaching equal levels of organization. Although these ideas were developed in the early decades of the century, these quotations are taken from an

32 On Grant and the other British transcendental anatomists see Desmond, The Politics of Evolution and Rehbock, The Philosophical Naturalists. 
English translation published as late as 1847, suggesting that Oken's more provocative views were still considered worthy of attention. ${ }^{33}$

Stephen Gould shows how the serial relationship was endorsed in a far more sober form by J. F. Meckel in 1811. Like Oken, Meckel accepted that nature was governed by a unified set of laws and that these laws directed the course of its development through time. His paper's title is, in Gould's translation: 'Sketch of a Portrayal of the Parallels That Exist between the Embryonic Stages of Higher Animals and Adults of Lower Animals'. The parallels are illustrated with examples drawn from comparison between the human embryo and the lower animals, including invertebrates. The heart in particular passes though fish-like and reptilian stages of development. The same points were made independently by Étienne Serres in a series of papers published from 1824 onwards. Serres was no idealist, being a follower of the more materialistic version of transcendental anatomy active in France. He declared that his work 'has proven that lower animals are, for certain of their parts, permanent embryos of higher classes'. ${ }^{34}$ Both wings of the transcendentalist movement in anatomy, German idealism and French materialism, thus converged on the law of parallelism or what E. S. Russell called the 'Meckel-Serres law', although he also added the names of Friedrich Tiedemann in 1808 and K. G. Carus in 1834 to the list of supporters. This law would serve as the basis for the theories of recapitulation that would flourish in the age of evolutionism.

The law of parallelism allowed the Lamarckians' appeal to a linear progressive sequence to be seen as evidence for the existence of an inherent developmental trend in nature with the human form is its high point or goal. The new approach was exploited in early nineteenth-century Britain by radical thinkers seeking to challenge conservative religious and social views. Eventually, though, the new transcendental or philosophical anatomy entered the mainstream of scientific thought. De Blainville's work was translated by Robert Knox, and linear sequences were recognized within many classes by Peter Mark Roget, the young William Benjamin Carpenter and others. ${ }^{35}$ However great the diversity of life, it was still possible to see a progressive sequence within the vertebrate type leading up to the human form.

\section{Fossils and Progress}

Through the eighteenth century there had been a growing awareness that the complexity of the earth's crust revealed huge changes that were hard to explain

33 Oken, Elements of Physiophilosophy, quotations from pp. 492-4; see Richards, The Romantic Conception of Life, esp. chap. 11.

34 E. R. A. Serres, 'Explication du système nerveaux des animaux invertébrés' (1824), p. 378, trans. in Gould, Ontogeny and Phylogeny, p. 48; see also Russell, Form and Function, chaps. 6 and 7.

35 See Rehbock, The Philosophical Naturalists, esp. pp. 49-52, 59 and 63. 
except on the assumption that the planet is much older than the traditional account based on Genesis had assumed. There was a sequence of rock strata superimposed in an order that allowed one to argue that the lowest was the oldest. Massive disruptions after deposition implied major earth movements and volcanic events. By the 1830s the main outlines of the geological periods we still accept today had been established. It was still widely assumed that the periods were defined by catastrophic events that served as the 'punctuation marks' in the sequence, but the sequence itself was becoming clearer.

There was also an expanding knowledge of the fossils contained in the strata, now no longer dismissed as curiosities but accepted as the remains of the earth's former inhabitants. The populations of the successive periods were very different and often included forms unlike anything alive today. This made the possibility of a erecting a genuinely unilinear arrangement of organic forms even more implausible and also undermined the principle of plenitude by confirming the reality of extinction. At the same time, though, the fossil record did seem to reveal evidence of a basic sequence in the introduction of the main vertebrate classes, a sequence which corresponded to the series implied when the law of parallelism was applied to the human embryo. The implications of this model of development aimed towards the mature human form were extended to include the actual progress of life on earth. The result was what Loren Eiseley described as a transcendental, man-centred progressionism very reminiscent of the temporalized chain of being. ${ }^{36}$

Martin Rudwick has provided the most extensive histories of the work done by these pioneering earth scientists. ${ }^{37}$ Dramatic changes in the conditions under which rocks were laid down were assumed to be the product of catastrophic events separating long periods of relative stability. William Whewell coined the term 'catastophism' to identify this approach, contrasting it with the 'uniformitarianism' proposed by Charles Lyell in the 1830s. Lyell argued that it was more scientific to assume that all changes in the past were brought about by agents identical to those we see in operation today. He insisted that the earth must be immensely old in order that such slow changes could produce the transformations observed in the crust. The catastrophists wanted a more limited time-span, but they were by no means exponents of a 'young earth', being quite willing to acknowledge that millions of years were involved.

Systematic changes in the populations of invertebrates were used to define the geological periods, but it was the ancient vertebrate forms that were most exciting to the general public. Cuvier studied mammals such as the mammoth and the mastodon - huge and impressive beasts, their fossil skeletons widely

${ }^{36}$ Eiseley, Darwin's Century, pp. 94-7.

${ }^{37}$ Rudwick, Earth's Deep History; for more details see the same author's Bursting the Limits of Time and Worlds before Adam. 
displayed in museums. They were so large that Cuvier was able to convince everyone of the reality of extinction. Now that the earth was better explored it was impossible to believe that such creatures still survived in some remote location. Soon giant reptiles were being discovered, culminating in the first known dinosaurs. By the 1840s the notion of an 'Age of Reptiles' preceding that of the mammals had become commonplace. Below this was a series of formations from which only fish were known, while the oldest fossil-bearing rocks contained only strange invertebrates such as the trilobites. There were occasional anomalies, and Lyell was able to argue that the sequence was not quite so clear-cut, a few primitive mammals appearing in the middle of the Age of Reptiles. On the whole, though, the sequence of creation represented what most commenters regarded as an obvious progression from the simplest forms through the vertebrate classes to the mammals and finally humans. It was taken for granted in the early nineteenth century that there are no human fossils and that we are the most recent creation. ${ }^{38}$

Conservative naturalists, especially in Britain, still assumed that the progression worked through a series of miraculous creations. Extinction was assumed to be sudden, the result of catastrophic upheavals in the earth's crust. If these revolutions were global the planet would have to be repopulated from scratch, so miracles were the only explanation. Continental scientists were less inclined to invoke the supernatural, but their theories of underlying patterns and trends were equally linked to discontinuity. Some even though that the powers embedded in nature itself could generate higher forms of life spontaneously. More often the actual process by which new forms of life emerged was left discretely unexplained. There was still a wide reluctance to accept the possibility that new species could be produced by the transmutation of old ones. The conviction that the history of life displayed a progressive trend leading towards humankind did not immediately lead to the emergence of a consensus in favour of what we call evolutionism.

There were some attempts to explain the progress of life in terms of adaptations to the improving physical environment. But it was also possible to exploit the similarity between the sequences observed in the fossil record and in the development of the human embryo. The parallel became a symbol of our position at the head of creation: this was the 'transcendental, mancentered' vision of the progress of life on earth. Its leading proponent was the Swiss naturalist Louis Agassiz, later one of the founding fathers of American science. As a young man he had heard lectures from Oken, but he had also studied with Cuvier and learnt a more practical approach to the study of fossils. Agassiz was deeply religious, reinterpreting the transcendentalists'

38 See Rudwick, The Meaning of Fossils and my own Fossils and Progress. 
philosophy of an underlying unity of nature in terms of a divine plan of creation. He also took the term 'creation' literally, remaining a staunch opponent of evolutionism throughout his life. He provides a classic example of a naturalist who is well aware that the overall pattern of relationships within the animal kingdom is too complex to be reconciled with a linear chain of being, yet is still anxious to see a main line of development running through the whole towards humankind as the pinnacle of creation. He linked the hierarchical sequence of classes with the development of the higher embryos and the order in which the forms appear in the fossil record, all interlocking aspects of a coherent divine plan which unfolds through the earth's history and is recapitulated in the development of every modern embryo.

Agassiz made his reputation in the 1830s with a comprehensive study of fossil fish. Within this class he was well aware of the diversity of forms. He recognized that the law of parallelism could be applied within each fish family - the highest modern representatives of the family having embryos that recapitulated earlier forms in the series. At the same time, however, he insisted that when we step back to take an overview of the whole sequence of vertebrate creation, we see a linear development pointing towards the human form as the goal of creation. As he declared in an inaugural lecture at the Academy of Neuchâtel in 1842:

The history of the earth proclaims its Creator. It tells us that the object and the term of creation is man. He is announced in nature from the first appearance of organized beings; and each important modification in the whole series of these beings is a step towards the definitive term of the development of organic life. It only remains for us to hope for a complete manifestation in our epoch of the intellectual development which is allowed to human nature. ${ }^{39}$

Note here the link between the idea of progress in earth history and the hope of progress in human history today: it wasn't only the evolutionists who saw the one process as evidence for the other.

Agassiz continued to expound these views in books and articles through the rest of his career. In his Outlines of Comparative Physiology (written in collaboration with A. A. Gould), for instance, he stresses that the connections between successive forms is ideal, not material, so we are witnessing a divine plan that announces its end-point from the beginning:

The link by which they are connected is of a higher and immaterial nature; and their connection is to be sought in the view of the Creator himself, whose aim, in forming the earth, in allowing it to undergo the successive changes which geology has pointed out, and in creating successively all the different types of animals which have passed away,

39 Agassiz, 'On the Succession and Development of Organized Beings at the Surface of the Terrestrial Globe', p. 399. On his career see Lurie, Louis Agassiz. 
was to introduce Man upon its surface. Man is the end toward which all the animal creation has tended, from the first appearance of the first Palaeozoic fishes. ${ }^{40}$

His vision of the plan of creation became more complex in time, and the idea of a linear progress pointing to humanity less clear-cut, but later works such as the Essay on Classification, written after he moved to America, still made it clear that the pattern of natural relationships must be seem as a coherent divine plan in which the eventual appearance of humankind is prophesied from the beginning. ${ }^{41}$ Progress along the scale of organization has a predictable end-point.

Agassiz was by no means the only exponent of transcendental anatomy to see a link through to the appearance of humanity within the complex development of the animal kingdom. Richard Owen became Britain's best-known anatomist, hailed for his work introducing the new methods and using them to throw light on the relationships between animal forms. He emerged as a staunch opponent of the radical transformism of Lamarckians such as Grant. At first sight, he seems an unlikely candidate to be identified with a linear model of progress. He was best known for his theory of the vertebrate archetype, the underlying basic form of the vertebrate skeleton from which all the actual species can be derived, the modifications branching out in many different directions. Yet in the conclusion to his On the Nature of Limbs of 1849 he too falls back on the belief that within the diversity we can see a definite line of development leading towards the human form. He argues that 'recognition of an ideal Exemplar of the Vertebrated animals proves that the knowledge of such a being as Man must have existed before Man appeared. For the Divine mind which planned the Archetype also foreknew all its modifications.' He then concludes:

To what laws or secondary causes the orderly succession and progression of such organic phenomena may have been committed we are as yet ignorant. But if, without derogation of the Divine power, we may conceive the existence of such ministers, and personify them by the term 'Nature', we learn from the past history of our globe that she has advanced with slow and stately steps, guided by the archetypical light, amidst the wreck of worlds, from the first embodiment of the Vertebrate idea, under its old Ichthyic vestment, until it became arrayed in the glorious garb of the human form. ${ }^{42}$

Owen seems here to come perilously close to advocating a kind of divinely planned transmutation, a position he backed away from in the 1850 s only to return to after Darwin published.

40 Agassiz and Gould, Outlines of Comparative Physiology, pp. 417-18.

41 Agassiz, Essay on Classification, p. 167.

42 Owen, On the Nature of Limbs, pp. 85-6. The edition cited has introductory material by Ron Amundson and Brian K. Hall on the significance of Owen's ideas. See also Rupke, Richard Owen. 
Owen and Agassiz were quoted side by side on this topic in Hugh Miller's Testimony of the Rocks, a popular exposition of the implications of the latest fossil discoveries. Miller was an enthusiastic follower of Agassiz and an equally prominent opponent of all forms of transmutation. He would later extend the law of parallelism to the whole life-cycle of the organism, including senility and death, arguing that within each class we see not progress but decline, so there can be no continuous progression as the transmutationist requires. ${ }^{43}$ There were discrete episodes in the history of life marked by the sudden appearance of new types at a time when the previously dominant type had begun to decline. Agassiz could also point to the fact that in many forms of life individual development itself is discontinuous, as in the metamorphosis of insects.

A less idealized element of progression was included in the work of the German palaeontologist Heinrich Georg Bronn. His Untersuchungen über die Entwicklungsgesetze der organischen Welt of 1858 was submitted for a prize offered by the Paris Academy of Sciences for the best survey of the trends that could be observed in the fossil record. Like Owen, Bronn was keen to display the many branches that spread out from the primitive origins of each group, leading to a variety of specialized adaptive forms. But he did not believe that the overall pattern could be explained completely in terms of adaptation to the earth's changing conditions. There was, in addition, a distinct progressive trend pushing each group on the whole towards higher levels of organization. Bronn even seems to have believed that, left to itself, this trend would have produced a linear scale - but it was distorted over and over again by the need for organisms to adapt to their environment. There was nothing here to suggest a mystical trend towards the human form, but the diagram Bronn used to illustrate his position resembled a tree with a main trunk leading vertically upwards towards humanity (see Figure 2.2). Lines lead off on every side, but they are side-branches of the main line of development, leaving the impression that there is a linear hierarchy buried within the diversity of animal forms. ${ }^{44}$

Bronn later produced a German translation of the Origin of Species, but at this point he was not an evolutionist. He was, however, contributing to a general trend by which palaeontologists were becoming aware that as more fossil discoveries were made, they tended to fill in gaps in the record. In the early decades of the century it had been easy to dismiss transformism by simply pointing to the huge discontinuities in the sequence of fossil forms. Gaps still remained, but most of them were getting smaller as new discoveries

43 Miller, The Testimony of the Rocks, pp. 191-2. On Miller's views see Bowler, Fossils and Progress, chap. 4.

44 See Bowler, Fossils and Progress, pp. 108-10. I have used the French translation of Bronn's work, Essai d'une réponse a la question de prix proposée en 1850 par l'Académie des sciences. See also Gliboff, H. G. Bronn, Ernst Haeckel and the Origins of German Darwinism, although Gliboff takes a very different view of the issues from my own. 


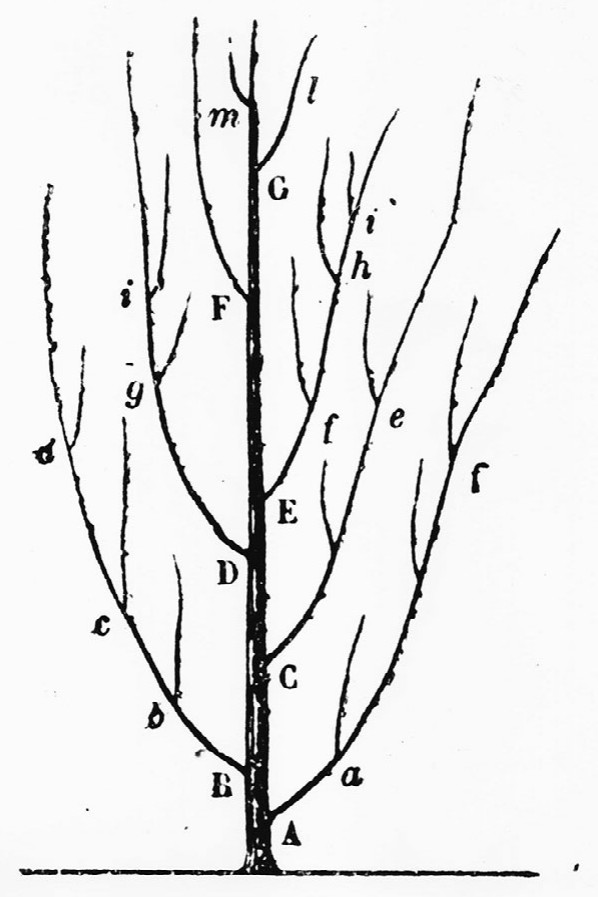

Figure 2.2 Tree-like representation of the development of the animal kingdom with a central trunk defining the main line of advance.

From H. G. Bronn, Essai d'une réponse a la question de prix proposée en 1850 par l'Académie des sciences (1861), p. 524

fitted into the sequence and the case for transformism no longer seemed quite so absurd. In the 1840s the argument that the progress shown by the fossil record was evidence for a continuous progressive trend in nature was placed on a new footing and had become the basis for an extended and often acrimonious debate. No one could believe that the history of life on earth was a simple ascent of the chain of being, but few could doubt that there was progressive trend involved. The question of whether that trend might unfold continuously via the gradual transmutation of species now became crucial, although the expectation that the trend had a preferred direction and goal remained.

\section{Problems with Continuity}

The original chain of being was seen as absolutely continuous, but for practical reasons most naturalists wanted to believe that species are distinct entities, 
links in a slightly discontinuous chain. This element of limited discontinuity remained a key feature of most attempts to explain not only the diversity of life but also its progress through geological time. The conservative thinkers who thought that species were created by God had obvious reasons for accepting the reality of their separate forms. But the radicals who argued for a natural process of what would later be called evolution faced a problem. If species are clearly separated from one another, surely they must be formed by discontinuous steps - the theory of evolution by jumps or 'saltations'. In fact this is a false assumption: if evolution is divergent, the process of change can be continuous but will give rise to gaps between the species produced when a line of development splits into two tracks that move gradually further apart.

The catastrophist vision of earth history introduced discontinuity at a more drastic level. The individual populations found in each geological period were certainly distinctive and could thus be seen as the products of discrete creative acts. But studies of the fossil record also suggested that there were a small number of much more dramatic transformations in the kinds of animals inhabiting the earth, episodes in which entirely new classes of creatures with new levels of complexity were introduced. These were the major discontinuities defining the ages dominated by fish, reptiles and mammals preceding the final creation of humanity. This latter step too could be seen as a step towards an entirely new level or organization, in this case defined by the emergence of mind and spirit. The catastrophist model of progress was thus radically discontinuous. It was a step-by-step ascent, each step upwards being represented as the rise to dominance of a new level of organization. Some catastrophists drew an analogy with the days of creation recorded in Genesis.

On such a model history is certainly a development towards a preordained goal, but it is also a process that proceeds by discrete upward leaps. It could even be argued that after each upward leap the higher class that had been introduced faced a gradual decline during the period of its dominance. Progress occurred in sudden advances, each gradually subsiding before the next upward step. This synthesis of the progressionist and cyclical world-view pictured the advance as analogous to the waves surging forwards as the tide comes in. There was an obvious analogy with the rise and fall of empires in human history that did not go unremarked. ${ }^{45}$

The emergence of Darwinism has been presented as the triumph of a more continuous model of development, but the triumph was limited because the discovery that there were apparently sudden breakthroughs in the ascent of life did not go away and eventually had to be incorporated into the modern view of

45 On the cyclic model in palaeontology see my The Invention of Progress, chap. 6. 
evolution. The 'uniformitarian' view of change as always continuous, proposed in Charles Lyell's Principles of Geology (1830-3) and taken up by Darwin, was unable to displace this one element of the catastrophist position. Darwin followed Lyell in arguing that the apparently dramatic appearance of new types was an artefact of the 'imperfection of the geological record': the slow intermediate phases had simply not left any records in the rocks (or they had been obliterated by later geological events). In fact the continued expansion of palaeontological evidence did not erode the validity of the initial perception that there were indeed discrete episodes in the development of life on earth. In this respect the element of discontinuity promoted by catastrophism represented a valid insight that would be integrated into the Darwinian world-view only by the palaeontologists of the early twentieth century.

\section{Development and Evolution}

In the decades during which Darwin developed his theory in secret there were occasional efforts to promote the Lamarckian suggestion that new species are produced not by miracle but by the transmutation of existing forms. These ideas often incorporated the assumption that the changes would take the form of abrupt leaps to new levels of organization. The most influential initiative came in a book published anonymously in 1844 under the title Vestiges of the Natural History of Creation. The author, whose name would not be revealed until much later, was the Edinburgh publisher and amateur naturalist Robert Chambers. His publishing house issued books and magazines aimed at the rising middle classes, and he was committed to the expectation of social progress. His aim in Vestiges was to bolster the case for reform by showing that progress was a universal trend: politics would merely facilitate the advance towards better things that was inherent in the laws of nature. Chambers believed that the experts who insisted that the fossil record was too discontinuous to support the case for transmutation were short-sighted. If one stepped back and looked at the overall trend it was obvious that there was a law of development running through all of nature, a law that should serve as the basis for our hopes for the future. This was what the historian of the Vestiges controversy James Secord called the "popular science of progress'. 46

There was, however, a curious mismatch between Chambers's view of biological evolution and his hopes for society. When Herbert Spencer moved in a similar direction a decade or so later, he ensured that the mechanisms he invoked to explain biological progress were exactly the same as those he expected to work in society (in his case the Lamarckian theory, later

\footnotetext{
46 Secord, Victorian Sensation; see also Hodge, 'The Universal Gestation of Nature'.
} 
supplemented by natural selection). Whatever Chambers hoped to achieve in society, his vision of the progress of life on earth provided nothing more than a loose analogy. Species were driven up the hierarchy of organization by an inbuilt trend that was somehow predetermined within the forces governing embryological development. There was no naturalistic explanation of how new characters were shaped in the sense that Darwin was looking for. Progress to a new level was purely automatic, driven by a plan somehow embedded in the fabric of nature by its Creator. Chambers took the idealist vision promoted by Agassiz and Owen and argued that the pattern unfolded by law rather than by a series of miracles. This was exactly what Owen seemed to hint at in his On the Nature of Limbs. The claim was controversial not just because it made the Creator's involvement seem more remote, but also because it entailed seeing humankind as a modified form of the highest animals.

Vestiges showed how the earth's formation and development could be accounted for by natural law. The origin of life was also supposed to be a purely natural process; like Lamarck, Chambers assumed that it was brought about by electrical activity and that the formation of very simple living things was still going on today. The fossil record showed how the very first organisms gradually developed over vast periods of time towards higher levels of organization. Every effort was made to minimize the significance of any gaps or apparent leaps so that the whole process could be seen as more or less continuous and hence due to the transformation of forms over successive generations. The ultimate source of new characters was derived from the forces governing embryological development, producing a series of small but still discrete upward steps:

the simplest and most primitive type, under a law to which that of like production is subordinate, gave birth to the next type above it ... that again produced the next higher, and so on to the very highest, the stages of advance being in all cases very small namely, from one species to another, so that the phenomenon has always been of a simple and modest character. ${ }^{47}$

Chambers envisaged the law of progress operating through extensions of the normal process of embryological development. Perhaps when stimulated by a change in the environment, development could advance to the next stage in the hierarchy, resulting in a small jump to the next highest species.

As to what actually determined the additional structure produced by this effect, Chambers had no answer other than to suggest that it was predetermined by the law itself: in effect the law was nothing more than the unfolding of a plan of development built into nature. Two elements within the first edition of Vestiges, soon abandoned in later printings, illustrate the source of this way of

${ }^{47}$ [Chambers], Vestiges, p. 222. 
thinking. A whole chapter was devoted to the circular or quinary system of classification devised by William Sharpe MacLeay. This imagined superimposed circles each of five elements: the animal kingdom was composed of five types, each type of five classes, each class of five orders and so on down to each genus composed of five species. It was a highly artificial system, a perfect example of the obsession with the hope of finding order and regularity hidden in the diversity of nature. Chambers appealed to it because it fitted his belief that there was a predetermined pattern built into the plan of development even though a system based on circles didn't really correspond with his notion of a developmental scale (which is presumably why it disappeared from later editions of his book).

The other strange feature of the first edition was its use of an idea proposed in Charles Babbage's Ninth Bridgewater Treatise, an unofficial addition to a series of books commissioned to display how the wisdom and benevolence of God could be seen in nature. Babbage is remembered today as a pioneer of the computer - he actually built a mechanical computer that could be programmed to undertake a series of tasks one after the other. In his Bridgewater Treatise he used an analogy based on his invention to argue that God could have arranged for miracles to occur not through His immediate intervention but by programming (to use the modern term) the laws of nature to jump to a new function at a predetermined point in time. Chambers was able to argue that the short extensions to development required by his theory were built into the laws in the same way. This suggests that he was thinking of progress as the unfolding of a divine plan built into nature at the creation, not the product of laws operating in the normal mechanistic fashion. In principle, anyone who could work out the pattern would be able to predict its eventual products, just as Agassiz and Owen believed.

This leaves the crucial question of just what the shape of the plan or pattern was supposed to be, and here there has been some disagreement among historians. Chambers was aware of von Baer's embryology which made it impossible to construct a linear hierarchy of forms: each class develops in its own way and never passes through adult stages of other classes. But I suggest that Chambers offers us another example of how to imagine a linear hierarchy buried within a system of branching relationships. He gave a simple diagram, modified from one published earlier by the physiologist William Benjamin Carpenter, which shows the classes branching off separately from a vertical stem (see Figure 2.3). But the vertical stem still defines the 'main line' of development leading up to the mammals and then ultimately to humankind. A fish, for instance, develops along the main line of development until it reaches the point defining the fish level in the scale, after which it branches off to form the more detailed aspects of its mature structure. A reptile will carry on further up the scale before branching off, and so on. There is certainly 


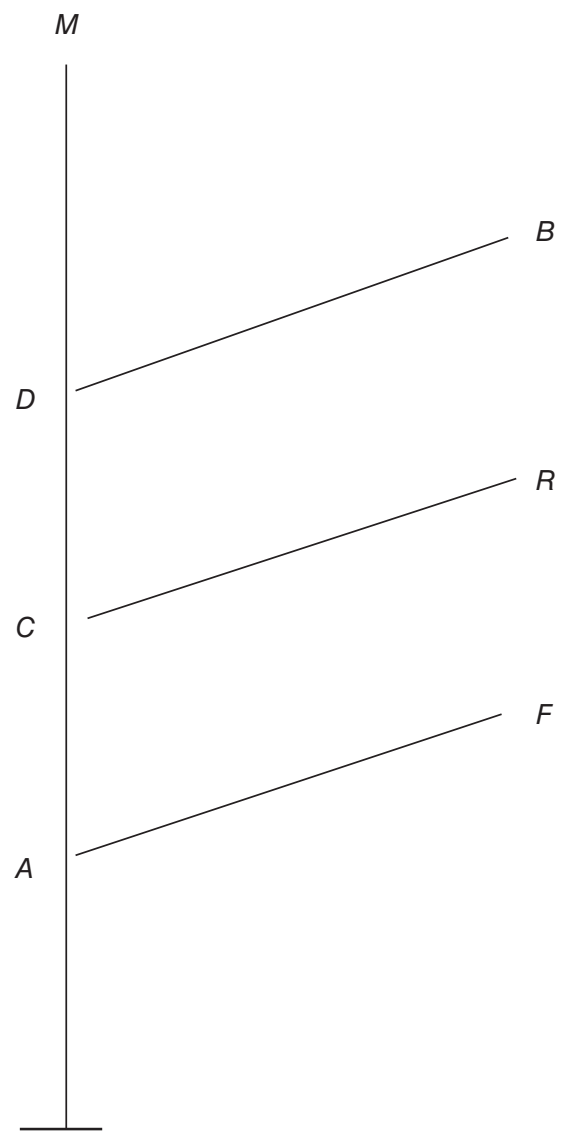

Figure 2.3 Simplified tree of development in the animal kingdom, with branches representing the classes branching from a main line leading towards the mammals. $\mathrm{F}$ denotes the fish, $\mathrm{R}$ the reptiles, $\mathrm{B}$ the birds and $\mathrm{M}$ the mammals.

From Robert Chambers, Vestiges of the Natural History of Creation (1844), p. 212

branching in the plan, but there is also a linear scale defining the main line of development which leads up to humanity. We are still meant to regard ourselves as the intended goal of creation; the lower forms are just sidebranches leading to dead-ends.

In later editions of Vestiges Chambers struggled to work out how his system could be applied to explain the complexity of the animal kingdom. He suggested that evolution (as we would call it today) proceeds through a number of parallel lines all advancing through the same hierarchy of 
complexity within its class. He even hinted that a line can pass from one class to another, in effect making each class polytypic, having a number of independent ancestors. He also suggested that each line must begin with an aquatic form and then evolve terrestrial equivalents. Most of these strange phylogenies are constructed from living forms with little reference to what would make sense in terms of the fossil record.

Chambers's book made no effort to conceal his main point: that the human race was the final product of the most active line of development and that we had originated by a small change from some highly developed animal ancestor (curiously he made no effort to identify this with the apes). Where the traditional view saw the human mind as existing on a higher plane than anything available to the animals, he argued that an increase in the size and complexity of the brain could explain how our mental and moral faculties had emerged from those of the animals. He appealed to phrenology, a popular amalgam of science and social philosophy which held that the structure of the brain determined an individual's mental capacities. If the brain is the organ of the mind, then expanding the brain via an evolutionary jump would explain how we had advanced mentally beyond our animal ancestors. Phrenology was tied in with the ideology of social progress: since its practitioners claimed to be able to determine one's brain structure from the shape of the skull they could, for instance, advise people on the careers they were best suited to. ${ }^{48}$ Chambers also argued that there were laws governing how society operates, so that it was possible to identify regularities and thus predict future changes in crime rates and other social activities.

Compared with those of later evolutionists such as Spencer, Chambers's efforts to see social progress as a continuation of biological development were unconvincing. But his overall message was clear enough, and despite his efforts to present development as the unfolding of divine plan his linkage of humans to the animal kingdom was enough to offend many religious thinkers. There was a huge outcry and numerous rebuttals, often based on the discontinuity of the fossil evidence rather than any reasoned response to the theory's deeper implications. The book was a long-running sensation, the last edition (the eleventh) appearing in 1860, after the publication of the Origin of Species. Its impact on the public was considerable, and historians generally agree that Vestiges paved the way for the reception of Darwinism, if only by absorbing some of the shock that would otherwise have made the response to the Origin all the more acrimonious. We also need to be aware that in attracting so much public attention it may have shaped the way Darwin's book was read. People

48 There is a huge literature on phrenology; see for instance Cooter, The Cultural Meaning of Popular Science; Young, Mind, Brain and Adaptation in the Nineteenth Century; and Van Wyhe, Phrenology and the Origins of Victorian Scientific Naturalism. The debate over Vestiges is covered in detail in Secord's Victorian Sensation. 
had come to think of evolution as a purposefully designed progression leading to humankind. That wasn't what Darwin had in mind, but not all of those who read his book (or more often accounts of it published by others) would be able to appreciate that fact.

\section{Developmentalism in the Age of Darwin}

The theory of evolution proposed by Charles Darwin differed fundamentally from the vision of progress expounded in the pages of Vestiges. For Chambers, as for Agassiz and Owen, the pattern that shaped the history of life was linked to and (for Chambers at least) actually driven by the forces of embryological development. The resulting trends were predetermined and aimed towards the emergence of predictable goals. They had no naturalistic explanation because they were embedded in nature by its Creator, left to unfold before observers who could not penetrate to the underlying processes. Development was an intrinsically teleological process. It was conceded that there were many branches to the tree of life, but the human race was still seen as the high point of creation, defining a main line of development that formed the central trunk of the tree of evolution.

It was this developmental viewpoint that Darwin set out to challenge. $\mathrm{He}$ didn't deny that progress occurred, but he did not see it as an inherent force of nature, nor would he accept that it had a privileged axis running towards humankind. We may be higher than the other animals, but there was nothing inevitable about our emergence into a new world of mental and social evolution. Many of the other lines of evolution have progressed too - and many have degenerated - all at the mercy of ever-changing conditions to which they must adapt. Progress is a by-product of evolution, not its central purpose or driving force. Leaving aside the unsettling idea of natural selection acting on 'chance' variations, it was hard for Darwin's contemporaries to accept or even appreciate the full extent of the revolution he sought to bring about. Naturalists concerned with classification might accept the need to see evolution as a divergent tree with no central trunk, but for many ordinary people and most religious thinkers it was hard to throw off the sense that somehow the human race was meant to be here as the high point of creation.

There were numerous efforts to retain the impression that evolution was somehow intended to produce the human race, including evolutionary trees with obvious central trunks implying a main line of development. These were, admittedly, mostly in publications aimed at a wider public; trees constructed by working biologists were less obviously teleological. ${ }^{49}$ Theories of human origins, including surveys of the increasing number of hominid fossils, were

49 For a good selection see Pietsche, Trees of Life. 
more likely to present the material as evidence of a trend towards the fully developed human form. Evidence of the tendency to think in developmental terms can be seen in the theories of non-adaptive evolution and parallelism proposed by non-Darwinian biologists.

The extent to which developmentalism survived is bound up with the more general question of how scientists and the wider world tried to cope with the radical implications of Darwin's theory. I have argued elsewhere that our perception of how successful the 'Darwinian revolution' was at the time is skewed by a tendency to assume that everyone who pledged support immediately became a Darwinian in the modern sense of the term. In fact many who figure prominently in the defence of the theory retained doubts about the adequacy of the mechanism of natural selection and were less inclined than Darwin to face up to the possibility that evolution was completely open-ended and unpredictable. Even Thomas Henry Huxley, known as 'Darwin's bulldog', thought that selection would need to be supplemented by some process of predetermined variation that pushed groups to evolve in a particular direction. Some time ago I coined the term 'pseudo-Darwinism' to denote this position, and although it has not been widely accepted I still maintain that it is a valid way of drawing attention to the fact that not everyone was able to accept the implications of a theory in which adaptation to the environment is the only mechanism of change. ${ }^{50}$

The most contentious candidate for inclusion among the pseudo-Darwinians is the German biologist and social campaigner Ernst Haeckel. He proclaimed himself a supporter of the new theory and used it to promote his opposition to traditional religion based on a philosophy of 'monism' - the view that mind and matter are just different manifestations of a single substance whose activities are the sole determinant of how nature operates. Haeckel liked Darwinism because it seemed to support his claim that there was no divine purpose to be seen at work in the universe. He used it in a number of books that were popular both in Germany and in English translation. Yet historians disagree fundamentally over just how close Haeckel's thinking was to Darwin's. Robert Richards and Sander Gliboff argue that the links are substantial (although Richards blurs the issue by suggesting that Darwin himself owed much to the Romantic way of thinking). Others, including Michael Ruse and myself, think that the links are superficial and conceal Haeckel's commitment to a developmental way of thinking based on the inevitability of progress. ${ }^{51}$

50 The term 'pseudo-Darwnism' was coined in my The Non-Darwinian Revolution. For more detailed accounts of the evolutionary debates discussed in this section see also my The Eclipse of Darwinism and Evolution: The History of an Idea.

51 In addition to Gould's Ontogeny and Phylogeny and Gliboff's H. G. Bronn, Ernst Haeckel and the Origins of German Darwinism see Richards, The Tragic Sense of Lifet; di Gregorio, From Here to Eternity; and Richards and Ruse, Debating Darwin. 
The problem of interpretation is compounded by the very different areas of research that Darwin and Haeckel engaged in. Haeckel was a morphologist: he studied the structure of animals, especially their embryos, and his evolutionism was based on using this work to reconstruct the history of the animal kingdom, supplementing and to some extent bypassing the evidence from the fossil record. Darwin did morphological research too, notably in his study of the barnacles, but his real concern was how animals and plants interact with and are shaped by their environment. He had little interest in trying to reconstruct the details of how the various forms had evolved over geological time ('phylogenies', to use the term coined by Haeckel).

Haeckel also coined the term 'ecology', but he had limited interest in the topic. He paid little attention to other issues that were crucial to Darwin's way of thinking, including animal breeding and island biogeography (Gliboff notes that in translating the Origin, Bronn found the material on artificial selection particularly troubling). It is also obvious that whatever his endorsement of natural selection, Haeckel was far more interested in the Lamarckian theory of the inheritance of acquired characteristics. He preferred to believe that most new characters are produced by the organism's purposeful activity in response to the environment, not 'random' variation. This allowed him to argue that variation tends to be progressive; he knew that some evolution is degenerative but seldom focused on the topic.

It is partly this tendency to assume that most new characters represent an advance in the level of organization that leads the historians who question Haeckel's Darwinian credentials to see him as having a more developmental viewpoint. Lamarckism was also linked to the recapitulation theory, Haeckel's main contribution to phylogenetic research. For newly acquired characters to be inherited, it was thought that they had to be added on at the end-point of embryological development, thus preserving the old adult stage as a clue to ancestry.

Here we enter an area which has been fraught with misunderstanding. Stephen Gould's monumental study of the recapitulation theory focused on this Lamarckian component, especially visible in the work of a group known as the 'American neo-Lamarckians'. The leading figures here were Edward Drinker Cope and Alpheus Hyatt, and their efforts to reconstruct phylogenies were based on the claim that embryology preserves adult ancestral forms. They also saw the development of each animal group not as a branching tree but as a series of lineages advancing in parallel through the same developmental hierarchy, as though aimed at a predetermined goal. Since it was applied separately to each group, this project was not intended to restore a single linear chain of being, but it did retain the focus on linear patterns and it did see evolution as based on predetermined trends. Parallelism became a key feature of many non-Darwinian theories, and for Cope, at least, the Lamarckian 
theory allowed one to believe that evolution was the expression of God's purpose. $^{52}$

Gould thought that Haeckel's recapitulationism was cast in the same mould, but I now believe this to be a mistake that has confused the situation for decades. Richards and Gliboff are correct to argue that Haeckel's use of the principle was much less rigid, being compatible with von Baer's non-linear embryology because it acknowledged only the retention of ancestral embryonic stages. Nor was there any suggestion that evolution was driven along predetermined lines by inbuilt developmental patterns. In the end, though, I am still not convinced by the claim that Haeckel was a good Darwinian. One could argue that for him the Lamarckian process represented a progressive force that could be applied in many divergent branches in the tree of life. It would be Darwinian in the sense that it was compatible with an open-ended, unpredictable vision of evolution, although the progressive factor would certainly be stressed far more than Darwin himself would have allowed. But on some occasions at least, Haeckel does seem to encourage his readers to see the line of descent leading though to the human form as the main line of development. Here, at least, there is the retention of something like the temporalized chain of being. 53

It may be that this impression is an unintended by-product of Haeckel's approach to his subject. In parts of his popular works, including The History of Creation and more especially The Evolution of Man, he focused on showing his readers how their own species has emerged, which inevitably involved picking out the line that led towards the human form for special attention. This would create the impression of a predetermined line of advance, although in fact the 'main line' would be established by hindsight, identifying the transitions that became crucial for our own origins without implying that the steps were predetermined. Nevertheless, Haeckel's works and the other popular books which followed his lead helped to create a whole genre focused on the process of evolution leading towards humankind. Such books give the impression of a linear chain of developments leading towards a goal, even if there is no intention to imply that the human form is the predetermined end of creation. Haeckel also used extensive evidence from embryology rather than the fossil record, again creating an impression that development towards maturity was somehow analogous to the process of evolution.

52 Cope's theory is outlined in his The Origin of the Fittest and The Primary Factors of Organic Evolution. For his religious views see his The Theology of Evolution. On Cope and the other American neo-Lamarckians see Gould's Ontogeny and Phylogeny and my The Eclipse of Darwinism, chap. 6.

53 Pietsche, Trees of Life includes nineteen of Haeckel's trees, of which three have a main stem leading to humankind (although several are for the plant kingdom only). The 'knarled tree' is from The Evolution of Man, vol. 1, plate XV, facing p. 188. 
Haeckel provided several diagrams that show the tree of life with a central trunk running up to the human form. The most famous resembles a gnarled tree with braches leading off to the side at various levels towards the other animal groups (see Figure 2.4). The impression that there is a main line of progress aimed at a particular goal, and that all the other animals are just modified descendants of key stages in the ascent towards humankind, is hard to miss. There are many other phylogenetic diagrams in Haeckel's works that are perfectly compatible with an open-ended branching tree model. But in his History of Creation he listed twenty-two stages in 'The Chain of the Animal Ancestors, or the Series of the Progenitors of Man'. Again an apparently linear progress towards a predetermined goal emerges from the diversity of life. ${ }^{54}$ Darwin himself would not have felt comfortable with any means of presentation that gave the impression that the human species is the goal of evolutionary progress.

The same approach is visible in the work of other Darwinians. Anton Dohrn antagonized Haeckel by proposing an alternative to the latter's views that the vertebrates had evolved from the tunicates (sea-squirts). He proposed instead that they had evolved from arthropods and that the tunicates were a degenerate offshoot of the vertebrate stock. He then implied that more or less all the lower forms of life had degenerated at one point or another from a single progressive line of development: 'we gain the picture of a single lineage, which concealed within itself the germ of all remaining high, highest, and also lowest productions, whose descendants here span the universe with sense and thought .... 55

Dohrn's friend, the British zoologist E. Ray Lankester (who also wrote on degeneration), invoked the model of a single hierarchy in the animal kingdom from which all the lower types had branched off one after the other. As a good Darwinian, Lankester warned against the simple-minded assumption that some of the lower species today are 'living fossils' preserving earlier stages of development. Humans had not evolved from the chimpanzee or the gorilla but from some less specialized ancestral primate. Yet it was still possible to see the main line of development in outline:

the general doctrine of evolution justifies us in assuming, at one period or another, a progression from the simplest to the most complicated grades of structure; that we are warranted in assuming at least one progressive series leading from the monoplast to man; and that until we have special reason to take a different view of any particular case we are bound to make the smallest amount of assumption by assigning to the various

54 Haeckel, The History of Creation, vol. 2, pp. 278-94.

55 From Michael Ghiselin's translation of Dorhn's Der Ursprung der Wirbelthiere (1875), 'The Origin of Vertebrates and the Principle of Succession of Functions', p. 77. On the debate over vertebrate origins see Bowler, Life's Splendid Drama, chap. 4. 


\section{PEDIGREE OF MAN.}

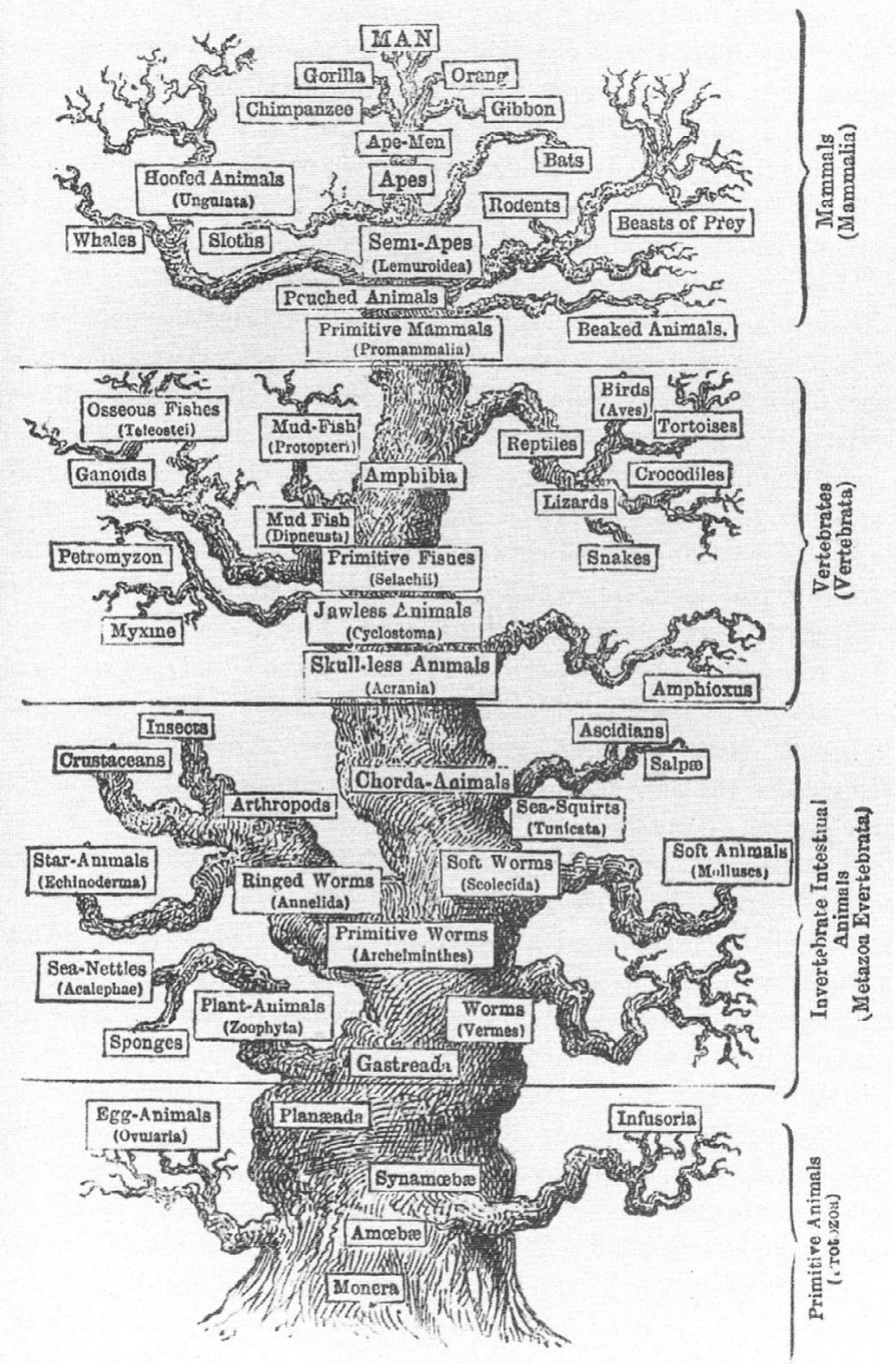

Figure 2.4 Tree-like representation of the evolution of the animal kingdom. Although gnarled like a real tree, the central trunk still implies a main line of development towards humans.

From Ernst Haeckel, The History of Creation (1876), vol. 2, facing p. 188 
groups of organisms the place will fit on the supposition that they do represent in reality the original progressive series. ${ }^{56}$

If there were still efforts to see a linear hierarchy in nature, there were few explicit attempts to revive Agassiz's claim that the human form is the intended goal of creation. For all that progress was the mantra of the age, so explicit a return to the traditional way of thinking would seem inappropriate to all except the most conservative thinker. Even Darwin argued that progress was inevitable in the long run, although he saw it as an irregular by-product of the relentless action of natural selection. In the course of his effort to present Darwin as a developmentalist, Richards notes a reference to the idea that 'Man is the one great object, for which the world was brought into the present state', but this is in one of his early notebooks and there is little to suggest he ever took it seriously. ${ }^{57}$

Outspoken opponents of Darwinism including Richard Owen and St George Mivart appealed to the orderliness of nature to defend the view that evolution was the expression of a divine power, but they seldom imagined linear patterns leading directly towards the human form. Their 'theistic evolutionism' was meant to retain the old vision of nature as a divine artefact but update it to accept a non-materialistic version of evolutionism. This was the position staked out in Chambers's Vestiges, and we have seen that in the late 1840s Owen seems to have shared the view that the unfolding of the divine plan was aimed at the production of humanity. As evolutionism became more popular in the decades after Darwin, he backed away from this position to concentrate on demonstrating regular patterns in the evolution of a diverse range of organisms. Mivart also took this approach in his highly anti-Darwinian Genesis of Species of 1871. Significantly, both were now anxious to argue for a separation between humans and apes in order to preserve our unique spiritual character. Arguing for a main line of evolution pointing towards humanity would have undermined their efforts - in this case worrying about continuity of development clashed with the idea of linear progress. ${ }^{58}$

Yet there were still some efforts to defend the idea that humanity is the goal. As late as 1884 the Glasgow professor of anatomy John Cleland claimed that 'man is a terminus, and not only $a$ terminus, but the terminus of the advance of vertebrate life'. 59 Those who wrote for a wider readership were more likely to stress the idea of progress and to present the human race as - if not the predetermined goal - then certainly as the highest product of evolution,

56 Lankester, 'Notes on the Embryology and Classification of the Animal Kingdom', p. 440.

57 Richards and Ruse, Debating Darwin, p. 164, see Charles Darwin's Notebooks, p. 409.

58 On theistic evolutionism see Bowler, The Eclipse of Darwinism, chap. 3, and more generally on these debates Desmond, Archetypes and Ancestors and Moore, The Post-Darwinian Controversies.

59 Cleland, 'Terminal Forms of Life', p. 359. 
thereby defining the most significant line of development. In America John Fiske converted Herbert Spencer's system of progressive evolutionism into a 'cosmic philosophy' in which the process was underpinned by divine power and led inevitably to the appearance of humanity and towards a civilization based on a liberalized Christianity. Fiske suggested that the extension of childhood in the human race promoted socialization and the emergence of the family and saw this as an example of several 'critical points' in evolution. ${ }^{60}$ Joseph LeConte also wrote of 'critical periods' in the advance of life, giving a diagram showing waves representing the rise and fall of successive classes in the history of life. He insisted that although evolution threw off many branches, all except one led off to specialization and stagnation. Humanity was the divinely planned outcome of this main line of development. ${ }^{61}$

A curious offshoot of the tendency to see evolution as the unfolding of predictable trends was the introduction of the concept of 'racial senility'. Here the analogy between evolution and the individual life-cycle was extended to its obvious conclusion: each line of development led inevitably to an ultimate decline and to death. Palaeontologists such as Alpheus Hyatt in America thought they could distinguish developmental sequences within the history of each class, each rising to a maturity and then declining towards degenerate forms and eventual extinction. In this profoundly non-Darwinian version of evolutionism, all the animal classes exhibited similar overall patterns of rise and fall. This was linked to the claim that within each class there were many parallel lines, each following the same predetermined path but perhaps at different rates. Hyatt's favourite examples were in the Ammonites, but the cyclic model of evolution was promoted by experts on a number of other classes including the dinosaurs.

The theory of parallel evolution driven by inherently developmental trends was anything but an endorsement of evolutionary progress, and indeed its implications were profoundly pessimistic. If applied to the human race it would imply that we too are predestined to decline to racial senility and extinction. Here we see the downside of the parallel drawn between evolution and the individual life-cycle. Those with a more optimistic view focused on the first phase of development up to maturity, conveniently ignoring the later phases. Faith in progress was retained by focusing on the upward steps in the development of the vertebrate classes. ${ }^{62}$

60 Fiske, Outlines of Cosmic Philosophy; see part 3 on the wider implications of the system. Spencer's views actually come closer to the more open-ended view of evolution and are discussed in Chapter 7 below.

61 LeConte, Evolution: Its Nature, Its Evidences and Its Relation to Religious Thought, p. 15 and p. 19. See Stephens, Joseph LeConte.

62 For details of Hyatt's work and other examples of the concept of racial senility see my The Eclipse of Darwinism, chaps. 6 and 7, and Life's Splendid Drama, chaps. 7 and 9. 
There were numerous popular contributions to the kind of evolutionary survey focused on the line of development leading to humankind. This was the age of what Bernard Lightman has called the 'evolutionary epic', and while some of these narratives were written from the naturalistic perspectives others were intended to convey a message more in tune with traditional beliefs. It was the struggle to develop the mental and ultimately the moral faculties that constituted the main driving force of evolution, and humanity was obviously the most successful outcome of this trend. Arabella Buckley, an enthusiast for spiritualism, published her Winners in Life's Race in 1882 to promote this optimistic vision of evolution. While she recognized that the birds deserved an honourable mention for their colonization of the air, there was no doubt that it was the mammals, the primates and ultimately humans which represented the triumph of vertebrate evolution. ${ }^{63}$ Religious thinkers shared these sentiments and inevitably gravitated towards the non-Darwinian theories. In 1894 Henry Drummond's Ascent of Man enjoyed huge success promoting the view that the struggle for existence was not the driving force of evolution; instead it was the drive to cooperate that led animals to progress, leading inevitably to the appearance of humanity's moral character. ${ }^{64}$

Buckley's enthusiasm for spiritualism was shared by the co-discoverer of natural selection, Alfred Russel Wallace. Although he saw selection as the only valid mechanism of evolution (even Darwin had allowed a minor role for Lamarckism), Wallace made an exception for the human mind, which he came to regard as being of supernatural origin. While well aware of the diversity of life, he was forced to accept that the main purpose of evolution was to produce a being capable of being endowed with a spiritual dimension. For those who accept the existence of a spiritual world 'the whole purpose, the only raison d'être of the world - with all its complexities of physical structure, with its grand geological progress, the slow evolution of the vegetable and animal kingdoms, and the ultimate appearance of man - was the development of the human spirit in association with the human body'. ${ }^{65}$ This view came to the fore in his last book, The World of Life: A Manifestation of Creative Power, Directive Mind and Ultimate Purpose, published in 1911. There was almost no mention of natural selection in this account of the progressive development of life towards a spiritual goal. The diversity of life was presented as a necessary background for the appearance of humankind and our future progress. The whole universe has been formed 'firstly, for the development of life culminating in man; secondly, as a vast school-house for the higher education

${ }^{63}$ On Buckley and evolutionary epics see Lightman, Victorian Popularizers of Science, chap. 5.

${ }^{64}$ On the response of religious thinkers including Drummond see Moore, The Post-Darwinian Controversies.

65 Wallace, The World of Life, p. 391.On Wallace's beliefs see Fichman, An Elusive Victorian, 
of the human race in preparation for the enduring spiritual life to which it is destined'.66

By the time Wallace published The World of Life its presentation would have begun to seem dated, its focus on our spiritual destiny all too obviously a product of Christianity's traditional message that humankind is the primary focus of the Creator's attention. From the earliest efforts to imagine a structure for the world of life and to investigate how that structure might have developed though earth history, the assumption that humanity was somehow the both the high point of creation and the intended goal of history had shaped naturalists' thinking. As the plausibility of the simple chain of being collapsed, this vision was preserved by insisting that the tree of life had a central trunk and that the human race lay at the head of this main line of development. This vision was now threatened by Darwinism, which made it much harder to think that the diversity of life concealed a man line of advance with a predetermined goal. Whatever Wallace's hopes in his declining years, the twentieth century would witness the triumph of this alternative way of visualizing evolution. For some, this meant the elimination of any hope of seeing evolution as progressive, but for others it would necessitate a reconfiguration of the idea of progress along less rigidly structured lines.

As we shall see in Chapter 6, this wasn't quite the end of the story. There have been occasional efforts to defend the claim that humanity is the predetermined outcome of evolution in the twentieth century. Some of these, indeed, are by eminent biologists, but they all reflect the conceptual driving force of what began as the linear model of progress represented by the chain of being. In effect this driving force is a conviction that somehow we humans are intended to be here by some higher power. Whether that power is divine or merely embodied in material nature, its intentions cannot be denied without depriving us of our crucial status in the world. A world that did not end up inhabited by something like ourselves is unthinkable.

Wallace's concern to argue that humanity's spiritual powers must have originated though supernatural action points to another problem that had been implicit in the linear model from the beginning. The original chain of being had been conceived as absolutely continuous, which would imply that there could be no break in the sequence between apes and humans: the apparent gap must be bridged by intermediates. This implication was also incorporated into any theory in which evolution was conceived of as a continuous process. Concern that this element of continuity would undermine our distinctive status had driven efforts to insist that species are discrete entities and that evolution would have to work in steps or jumps, the last of which would be the introduction of our mental and moral powers.

66 Wallace, Darwinism, p. 477. 
Darwin and the evolutionists challenged this sense of human uniqueness in the name of continuity. As the nineteenth century drew to a close, the crucial nature of the evolutionary step up to humanity was highlighted by the discovery of fossils that threw light on our immediate origins. Developments in evolutionary biology began to dovetail with new insights in areas such as anthropology and archaeology which challenged traditional assumptions about the original state of humanity. The resulting debates revisited issues that had emerged in the first efforts to explore the implications of continuity in the chain of being, issues that reveal a much darker side to its influence. 